\title{
PCR Multiplex fluorescente para detecção de bactérias em sêmen bovino ${ }^{1}$
}

\author{
Francisca E.F. Dias ${ }^{2 *}$, Caris M. Nunes ${ }^{3}$, Tânia V. Cavalcante ${ }^{2}$, Helciléia D. Santos ${ }^{2}$, \\ Silvia Minharro ${ }^{2}$ e José F. Garcia ${ }^{3}$
}

\begin{abstract}
Dias F.E.F., Nunes C.M., Cavalcante T.V., Santos H.D. Minharro S. \& Garcia J.F. 2012. [Fluorescent Multiplex PCR for detection of bacteria in semen bovine.] PCR Multiplex fluorescente para detecção de bactérias em sêmen bovino. Pesquisa Veterinária Brasileira 32(3):211-216. Escola de Medicina Veterinária e Zootecnia, Universidade Federal do Tocantins, BR 153 Km 132, Zona Rural, Araguaína, T0 77804-970, Brazil. E-mail: eldadias@uft.edu.br

This study aimed to evaluate the threshold of detection of fluorescent multiplex PCR coupled with capillary electrophoresis for detection of infectious agents in semen samples from experimentally infected with decreasing concentrations of the bacteria Brucella abortus, Leptospira interrogans serovar pomona, Campylobacter fetus and Haemophilus somnus. Samples of bovine semen were experimentally infected with decreasing concentrations of bacteria obtained from serial dilutions in the base 10 so as to obtain samples containing a long time until $10^{-7}$ bacteria/mL from the initial concentration of Lepstospira pomona, Brucella abortus, Haemophilus somnus and Campylobacter fetus. The dilutions were made individually for each bacterium, as well as in different concentrations needed to standardize the multiplex PCR test. DNA extractions of all solutions containing sperm and bacteria analyzed in this study were performed according to protocol described by Heinemann et al. (2000). The multiplex PCR products were analyzed by electrophoresis on $8 \%$ polyacrylamide gel and capillary electrophoretic separation system for automated equipment in the analysis of DNA fragments MegaBACE. We observed amplification of fragments of 193pb, 330pb, 415pb and 400bp from the DNA of B. abortus, L. pomona, H. somnus, C. fetus respectively. The analysis by capillary electrophoresis of multiplex PCR products of DNA for simultaneous detection of the four pathogens was observed by detecting the dilution of 10-3 bacteria / $\mathrm{mL}$ times the initial concentration of the stock solution of each bacterium. The multiplex PCR coupled with capillary electrophoresis was first used for the direct diagnosis of four pathogenic bacteria in semen, proving to be a rapid method to detect bacteria that cause reproductive disorders.
\end{abstract}

INDEX TERMS: Cattle, semen, bacteria, diagnosis, fluorescent PCR, capillary electrophoresis.

\begin{abstract}
RESUMO.- Este estudo teve como objetivo avaliar o limiar de detecção da técnica de PCR multiplex fluorescente aliada a eletroforese capilar na detecção de agentes infecciosos em amostras de sêmen experimentalmente contaminadas com concentrações decrescentes das bactérias Brucella abortus, Leptospira interrogans sorovar pomona, Campylobacter fetus e Haemophilus somnus. Amostras de sêmen bovino foram experimentalmente contaminadas com concentrações decrescentes de bactérias obtidas através de

\footnotetext{
${ }^{1}$ Recebido em 29 de agosto de 2011.

Aceito para publicação em 27 de outubro de 2011.

${ }^{2}$ Centro de Ciências Animal (EMVZ), Universidade Federal do Tocantins (UFT), BR $153 \mathrm{Km} 112$ s/n, Cx. Postal 132, Zona Rural, Araguaína, T0 77804-970, Brasil.*Autor para correspondência: eldadias@uft.edu.br

${ }^{3}$ Laboratório de Bioquímica e Biologia Molecular Animal, Departamento de Medicina Veterinária, Unesp, Rua Clóvis Pestana 793, Araçatuba, SP 16050-680, Brasil.
}

diluições seriadas na base 10 de modo a obter-se amostras contendo desde 1 vez até $10^{-7}$ bactérias/mL a partir da concentração inicial de Leptospira pomona, Brucella abortus, Campylobacter fetus e Haemophilus somnus. As diluições foram efetuadas individualmente para cada bactéria, bem como nas diferentes concentrações necessárias para a padronização do teste de multiplex PCR. As extrações de DNA de todas as soluções contendo espermatozóides e bactérias analisadas no presente estudo foram realizadas segundo protocolo descrito por Heinemann et al. (2000). Os produtos de PCR multiplex foram avaliados por eletroforese em gel de poliacrilamida $8 \%$ e separação eletroforética por sistema capilar em equipamento automático de análise de fragmentos de DNA MegaBace. Observou-se a amplificação de fragmentos de $193 \mathrm{pb}, 330 \mathrm{pb}, 400 \mathrm{pb}$ e $415 \mathrm{pb}$ a partir do DNA de B. abortus, L. pomona, H. somnus, C. fetus, respectivamente. $\mathrm{Na}$ análise por eletroforese capilar de produtos 
da PCR multiplex do DNA para detecção simultânea dos quatro patógenos observou-se a sinal de positividade até a diluição de $10^{-3}$ bactérias/mL vezes da concentração inicial da solução estoque de cada bactéria. A técnica de PCR multiplex aliada à eletroforese capilar foi usada pela primeira vez para o diagnóstico direto de quatro bactérias patogênicas no sêmen, demonstrando ser um método rápido na detecção de bactérias causadoras de doenças reprodutivas.

TERMOS DE INDEXAÇÃO: Bovino, sêmen, bactérias, diagnóstico, PCR fluorescente, eletroforese capilar.

\section{INTRODUÇÃO}

Considerando-se que um touro pode produzir até 500 doses de sêmen por ejaculado e que o uso de crioprotetores no processo de congelação possibilita a sobrevivência da maioria dos agentes infecciosos, torna-se possível a infecção de rebanhos pela utilização da inseminação artificial (Amin 2003, Rodrigues et al. 2003).

Atualmente, os métodos de diagnóstico utilizados para identificar os animais portadores de agentes infecciosos incluem: isolamento em meios de cultivo seletivos ou em cultivos celulares, inoculação em animais, soroneutralização, teste de fixação de complemento, ELISA, imunofluorescência indireta, hemaglutinação e imunodifusão (Ciceroni et al. 2002, Manterola et al. 2003).

Entretanto, a maioria destas técnicas apresenta limitações de ordem prática resultantes de execução, lentidão dos procedimentos laboratoriais para detecção e caracterização do agente infeccioso ou da infra-estrutura necessária para a sua realização. Além disso, limitações relativas à sensibilidade e especificidade tornam-se complicadores para a realização de diagnósticos práticos, precisos e de baixo custo (Amim 2003, Leyla et al. 2003, Manterola et al. 2003).

Por estes motivos nos últimos anos tem-se intensificado a busca por técnicas que possibilitem o diagnóstico das doenças infecciosas com maior rapidez, precisão, confiança e grau de sensibilidade e especificidade similares ou superiores aos de procedimentos convencionais (Bricker 2002).

Com o aumento do número de agentes microbianos detectáveis por PCR, essa ferramenta está se tornando conveniente para práticas de diagnóstico com propósito de detectar simultaneamente múltiplos agentes infecciosos que causem síndromes clínicas similares ou idênticas e/ou compartilhem características epidemiológicas semelhantes (Markoulatos et al. 2002).

Graças à grande versatilidade, a PCR proporcionou grande avanço nas técnicas de diagnóstico molecular. Variações da PCR foram desenvolvidas para atender a necessidades específicas. Algumas das mais amplamente utilizadas são: RT-PCR (Reverse Transcription-PCR), Nested PCR, Multiplex PCR, entre outras (Lunge et al. 2003).

Richtzenhain et al. (2002) utilizaram a PCR multiplex para detecção de Leptospira spp. e Brucella spp. simultaneamente em amostras de fetos bovinos abortados. Wang et al. (2002) desenvolveram um sistema PCR multiplex para deteç̧ão simultânea de genes das cinco principais espécies de Campylobacter de importância clinica, selecionando os genes: hipO e 23SrRNA de $C$. jejuni, o gene glyA de $C$. coli, C. lari e C. upsaliensis e o gene sapB2 de $C$. fetus subespécie fetus, isolados de amostras clínicas de humanos e aves domésticas.

Kim et al. (2001) usaram multiplex nested PCR para diferenciação de Circovirus porcino PCV-1 e PCV-2 em amostra de sêmen de caprino, demonstrando maior sensibilidade e rapidez do teste na diferenciação destes vírus. Estes mesmos pesquisadores em 2003 descreveram um multiplex seminested PCR para detecção e diferenciação dos mesmos vírus em sêmen de caprino concluindo ser esta técnica boa alternativa na diferenciação e detecção destes patógenos no sêmen da espécie.

Bor et al. (2003) utilizaram com sucesso PCR multiplex combinado com eletroforese capilar na identificação de microdeleções no cromossomo Y. Checa et al. (2002) utilizaram a eletroforese capilar para análise de variabilidade natural de frequência dos cromossomos $\mathrm{X}$ e $\mathrm{Y}$ em amostras de sêmen bovino, demonstrando a rapidez e sensibilidade da técnica.

Este estudo teve como objetivo avaliar o limiar de deteç̧ão da técnica de PCR multiplex fluorescente aliada à eletroforese capilar na detecção de agentes infecciosos em amostras de sêmen experimentalmente contaminadas com concentrações decrescentes das bactérias Brucella abortus, Leptospira interrogans sorovar pomona, Campylobacter fetus e Haemophilus somnus.

\section{MATERIAL E MÉTODOS}

O experimento foi desenvolvido no Laboratório de Bioquímica e Biologia Molecular Animal da Faculdade de Odontologia da UNESP, Campus-Araçatuba-SP. Para minimizar o potencial risco de contaminação de utensílios e equipamentos do laboratório com DNA foram tomadas precauções para manter os ambientes destinados à execução de cada etapa do procedimento de PCR (extração de DNA, manipulação de reagentes de PCR e eletroforese) fisicamente separados.

Amostras de sêmen bovino livre de patógenos, oriundas de diversos touros mantidos em regime de coleta semanal e sob rigoroso controle sanitário tiveram a concentração de espermatozóides determinada em câmara hematimétrica de Neubauer. 0 critério adotado para utilização do sêmen foi o fato de os animais doadores não apresentarem resultados positivos para os agentes em questão nas provas de rotina realizadas pela central de inseminação artificial (sorologia ou cultivo) para Leptospira, Brucella e Campylobacter. As centrais de inseminação artificial no Brasil não realizam rotineiramente testes para monitorar a presença de Haemophilus.

As cepas de Leptospira interrogans sorovar pomona e Brucella abortus foram gentilmente cedidas pelo Laboratório IRFA-Química e Biotecnologia Industrial Ltda, Porto Alegre, RS, Brasil. As suspensões bacterianas foram inativadas pelo calor a $100^{\circ} \mathrm{C}$ durante 15 minutos. A concentração de bactérias foi determinada no laboratório de origem pela contagem de células bacterianas em campo escuro e pela escala de MC Farland, respectivamente.

As cepas padrão das bactérias Haemophilus somnus (noㅡ 700025) e Campylobacter fetus subespécies fetus (n⿳2027374) foram adquiridas junto a American Type Culture Collection (ATCC), EUA. Campylobacter fetus foi cultivada no Laboratório de Sanidade Animal e Saúde Publica da UNESP Campus Botucatu (SP), empregando metodologia recomendada pela ATCC. Não foi possível 
a realização do cultivo da bactéria Haemophilus somnus, portanto foi efetuada diluição do estoque de bactérias em solução salina fisiológica, sendo a concentração de bactérias determinada através da escala de Mc Farland. Essa solução foi empregada para a contaminação experimental de amostras de sêmen.

A fim de determinar a menor concentração de DNA bacteriano capaz de ser detectado através da técnica de PCR multiplex fluorescente em amostras de sêmen contaminado com as diferentes bactérias, após descongelação o sêmen foi diluído em solução salina $0,9 \%$ para atingir a concentração de $30 \times 10^{6}$ espermatozóides/ $\mathrm{mL}$ em $500 \mu \mathrm{L}$ de solução, a qual denominou-se "dose inseminante". Estas foram experimentalmente contaminadas com concentrações decrescentes de bactérias obtidas através de diluições seriadas na base 10 de modo a obter-se amostras contendo desde 1 vez até $10^{-7}$ bactérias/mL a partir da concentração inicial de Leptospira interrogans sorovar pomona $\left(10^{8}\right.$ bactérias $\left./ \mathrm{mL}\right)$, Brucella abortus $\left(2,8 \times 10^{8}\right.$ bactérias/mL), Campylobacter fetus $\left(1,5 \times 10^{5}\right.$ bactérias/mL) e Haemophilus somnus $\left(1,5 \times 10^{5}\right.$ bactérias $\left./ \mathrm{mL}\right)$. As diluições foram efetuadas individualmente para cada bactéria, bem como nas diferentes concentrações necessárias para a padronização do teste de multiplex PCR.

As extrações de DNA de todas as soluções contendo espermatozóides e bactérias analisadas no presente estudo foram realizadas segundo protocolo descrito por Heinemann et al. (2000).

Foram utilizados oligonucleotídeos iniciadores previamente descritos na literatura, que amplificam região do gene $16 \mathrm{~S}$ rRNA de Leptospira sp. (Mérien et al. 1992), Brucella sp. (Leal-klevezas et al. 1995) e Haemophilus somnus (Angen et al. 1998).

Os oligonucleotídeos iniciadores para Campylobacter sp, foram desenhados com auxílio do Programa Primer Premier-5, a partir das sequências para os gene 16S rRNA depositadas no Genebank e posteriormente a identidade dos produtos foi comparada no software BLAST (http://www.ncbi.nlm.nih.gov/BLAST) (Stephen et al. 1997).

Um dos oligonucleotídeos pertencentes ao par específico para cada patógeno foi marcado com substância fluorescente FAM ou HEX (Invitrogen-Life Technologies ${ }^{\circledR}$ ).

As seqüências dos oligonucleotídeos iniciadores utilizados para os ensaios multiplex PCR, bem como os respectivos tamanhos dos fragmentos de DNA esperados após amplificação estão apresentados no Quadro 1.

Para atingir o sistema de multiplex PCR com os quatro patógenos, iniciou-se a padronização do teste com a detecção simultânea de Leptospira e Brucella, acrescentando-se em etapas subsequentes Haemophilus e Campylobacter, respectivamente.

As amostras de DNA obtidas foram submetidas à amplificação exponencial com os oligonucleotídeos iniciadores específicos acima descritos. As reações de amplificação foram realizadas em termociclador de temperatura programável (PTC-100 ${ }^{\mathrm{TM}}$ Programmable Thermal Controler, MJ-Research ${ }^{\circledR}$ ) e as condições da PCR estão apresentadas no Quadro 2.

Todos os ensaios de PCR com amostras contendo mais de um patógeno foram realizados em microtubos de $200 \mathrm{~mL}$, em volume final de $50 \mathrm{~mL}$ contendo: $200 \mathrm{mM}$ Tris-HCl pH 8,4 (Invitrogen-Life Technologies ${ }^{\circledR}$ ), 2,5mM cloreto de magnésio (Invitrogen-Life Technologies ${ }^{\circledR}$ ), 1,25mM de cada desoxinucleotídeo trifosfatado-dNTP (Invitrogen-Life Technologies ${ }^{\circledR}$ ), 10 pmol de cada oligonucleotídeo iniciador para Leptospira, Campylobacter e Haemophilus, 1 pmol de cada oligonucleotídeo iniciador para Brucella nas diferentes combinações, 1 Unidade de Taq Platinum DNA Polimerase (Invitrogen-Life Technologies ${ }^{\circledR}$ ) e água ultra pura (Invitrogen-Life Technologies ${ }^{\circledR}$ ) q.s.p para $50 \mathrm{~mL}$ além de $3 \mathrm{~mL}$ de amostra de DNA. Além disso, em cada ensaio foram incluídos controles negativos contendo todos os reagentes exceto DNA para monitoramento de
Quadro 1. Sequências dos oligonucleotídeos iniciadores específicos e os tamanhos dos fragmentos esperados de DNA amplificados por PCR multiplex (em pares de base - pb)

\begin{tabular}{|c|c|c|}
\hline Espécie & $\begin{array}{c}\text { Tamanho } \\
(\mathrm{pb})\end{array}$ & Oligonucleotídeos Iniciadores \\
\hline Brucella sp. & 193 & AA3'(FAM) \\
\hline Leptospira sp. & 330 & $\begin{array}{l}\text { 5'GGCGGCGCGTCTTAAACATG3' (HEX) } \\
\text { 5' TCCCCCCATTGAGCAAGATT 3' }\end{array}$ \\
\hline Haemophilus somnus & 400 & $\begin{array}{l}\text { 5'GAAGGCGATTAGTTTAAGAG3' (FAM) } \\
\text { 5'TTCGGGCACCAAGTRTTCA'3 }\end{array}$ \\
\hline Campylobacter & 415 & $\begin{array}{l}\text { 5'GTAGGCGGATTATCAAGTCT'3 (FAM) } \\
\text { 5'ATCAAGCCCAGGTAAGGTTC3' }\end{array}$ \\
\hline
\end{tabular}

Quadro 2. Condições de amplificações de DNA empregadas nos ensaios de PCR multiplex fluorescente após padronização, para detecção simultânea de diferentes bactérias em amostras de sêmen bovino contaminadas experimentalmente

\begin{tabular}{lc}
\hline \multicolumn{1}{c}{ Etapas } & $\begin{array}{c}\text { PCR multiplex fluorescente } \\
\end{array}$ \\
\hline Desnaturação inicial & $94^{\circ} \mathrm{O}-5 \mathrm{~min}$ \\
Número de ciclos & 35 \\
Desnaturação & $94^{\circ} \mathrm{O}-30 \mathrm{seg}$ \\
Anelamento & $57^{\circ} \mathrm{C}-30 \mathrm{seg}$ \\
Extensão & $72^{\circ} \mathrm{C}-30 \mathrm{seg}$ \\
Extensão final & $72^{\circ} \mathrm{C}-5 \mathrm{~min}$
\end{tabular}

possíveis contaminações, bem como controles positivos com DNA purificado de cultura bacteriana específica.

Os produtos de PCR multiplex foram avaliados por eletroforese em gel de poliacrilamida 8\% (Invitrogen-Life Technologies ${ }^{\circledR}$ ) corado com nitrato de prata (Merck ${ }^{\circledR}$, Alemanha). A eletroforese foi conduzida à temperatura ambiente em cuba vertical (Model V16-2 Life Technologies $\left.{ }^{\circledR}\right)$ com tampão TBE $(0,09 \mathrm{M}$ Tris-borato e 0,002M EDTA) (Invitrogen-Life Technologies ${ }^{\circledR}$ CA, EUA). As amostras foram submetidas a eletroforese por três horas a $100 \mathrm{~V}$ com o auxílio de uma fonte de alta voltagem (Power PAC 1000 BIO-RAD ${ }^{\circledR}$ ). Após o aparecimento das bandas, o gel foi colocado novamente em solução fixadora, onde permaneceu até ser analisado sobre luz branca e fotografado com aparelho de fotodocumentação (Kodak ${ }^{\circledR}$ Electrophoresis Documentation and Analysis System-120).

Os produtos da amplificação pela PCR multiplex foram também submetidos à separação eletroforética por sistema capilar em equipamento automático de análise de fragmentos de DNA MegaBace (GE Healthcare ${ }^{\circledR}$ ). A desnaturação das amostras foi feita misturando-se $2 \mathrm{~mL}$ de solução de PCR a $8 \mathrm{~mL}$ de Tween20 e $0,25 \mathrm{~mL}$ de marcador de peso molecular marcado com a substância fluorescente ROX (ROX-400 GE Healthcare ${ }^{\circledR}$ ). Em seguida realizou-se etapa de desnaturação a $95^{\circ} \mathrm{C}$ por 3 minutos em termocliclador de temperatura programável (PTC-100 ${ }^{\mathrm{TM}}$ Programmable Thermal Controler MJ-Research ${ }^{\circledR}$ ), sendo as amostras em seguida resfriadas em gelo e levadas ao equipamento automático de análise de fragmentos de DNA onde ocorreu eletroforese em sistema capilar. 0 tempo de corrida de cada amostra foi de aproximadamente 30 minutos, em polímero LPA Long Read Matrix 10x Buffer (GE Healthcare ${ }^{\circledR}$ ).

Para captura de dados da eletroforese do sistema MegaBace foi empregado o sofware Fragment Profiler. A análise dos resultados foi efetuada pela observação dos picos referentes aos fragmentos marcados com fluorocromos que geram diferentes comprimentos de onda, traduzidos em picos eletroforéticos de cores distintas. Mediante os eletroferogramas, as amostras foram caracterizadas pelo tamanho do fragmento esperado. Os tamanhos dos fragmentos foram analisados com auxílio do programa Fragment Profiler. 


\section{RESULTADOS}

Após contaminação de amostras de sêmen bovino individualmente com cada uma das quatro bactérias empregadas no presente estudo (resultados não mostrados), procedeu-se a PCR multiplex fluorescente utilizando-se oligonucleotídeos específicos foi possível observar a amplificação de fragmentos de $193 \mathrm{pb}, 330 \mathrm{pb}, 400 \mathrm{pb}$ e $415 \mathrm{pb}$ a partir do DNA de Brucella abortus, Leptospira interrogans sorovar pomona, Haemophilus somnus, Campylobacter fetus, respectivamente (Fig.1).

A Figura 1 apresenta o limiar de detecção simultânea por PCR multiplex fluorescente do DNA de amostras de sêmen. Foi possível detectar simultaneamente numa única reação sinal de positividade das bactérias até a diluição de $10^{-2}$ bactérias/mL a partir da concentração inicial da solução estoque de cada bactéria.

0 Quadro 3 apresenta os resultados da análise por eletroforese capilar de produtos das PCR multiplex fluorescente para detecção simultânea dos quatro patógenos, possibilitando a detecção até a diluição de $10^{-3}$ vezes da concentração inicial da solução estoque de cada bactéria.

\section{DISCUSSÃO}

O objetivo deste estudo foi desenvolver um PCR multiplex que possa superar em rapidez, sensibilidade e especificidade o diagnóstico das doenças transmitidas via sêmen através da monta natural e/ou inseminação artificial em animais de produção.

Apesar do fato de que medidas preventivas simples, envolvendo o manejo zootécnico e controle sanitário em centrais de inseminação artificial, tenham o objetivo de garantir a produção de sêmen com elevados índices de qualidade sanitária (Thibier \& Guerin 2000), o avanço tecnológico nos métodos diagnósticos em especial daqueles envolvendo rotinas de biologia molecular, apresentam um grande potencial para se tornarem testes de seleção e controle de touros doadores de

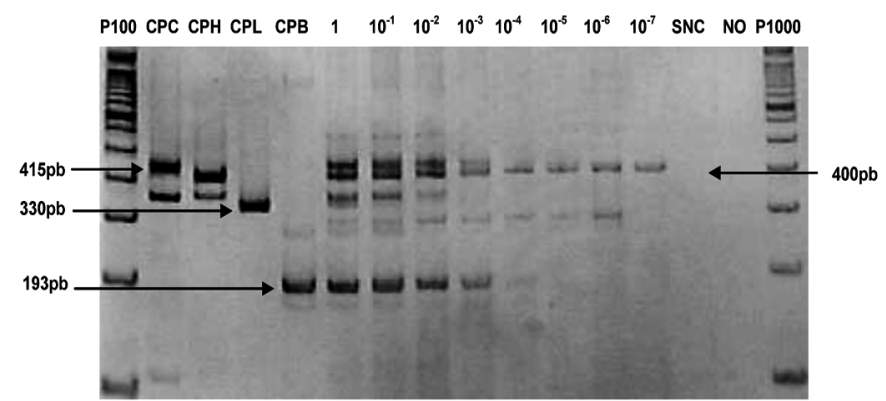

Fig.1. Eletroforese em gel de poliacrilamida 8\% corado com nitrato de prata. Produtos de amplificação por PCR multiplex fluorescente em DNA de amostras de sêmen bovino contaminadas experimentalmente com Campilobacter fetus, Haemophilus somnus, Leptospira interrogans sorovar pomona e Brucella abortus. P100) Marcador de peso molecular em escada de $100 \mathrm{pb}, \mathrm{CPC}$ ) Controle positivo de Campylobacter fetus, CPH) Controle positivo de Haemophilus somnus, CPL) Controle positivo de Leptospira interrogans sorovar pomona, CPB) Controle positivo de Brucella abortus, 1 a $10^{-7}$ ) Diluição seriada na base 10 das concentrações iniciais das soluções de referência de cada bactéria (item 4.2.3), SNC) Amostra de sêmen não contaminada, NO) Controle negativo (sem DNA).
Quadro 3. Detecção por eletroforese capilar de Campylobacter fetus, Haemophilus somnus, Leptospira interrogans sorovar pomona e Brucella abortus por multiplex PCR fluorescente em DNA de amostras de sêmen contaminadas experimentalmente

\begin{tabular}{ccccc}
\hline \multirow{2}{*}{ Amostra } & \multicolumn{5}{c}{ Eletroforese capilar } \\
\cline { 2 - 5 } & C. fetus & H. somnus & L. pomona & B. abortus \\
\hline CPC & + & - & - & - \\
CPH & - & + & - & - \\
CPL & - & - & + & - \\
CPB & - & - & - & + \\
1 & + & + & + & + \\
$10^{-1}$ & + & + & + & + \\
$10^{-2}$ & + & + & + & + \\
$10^{-3}$ & + & + & + & + \\
$10^{-4}$ & + & + & - & + \\
$10^{-5}$ & - & + & - & + \\
$10^{-6}$ & - & + & + & + \\
$10^{-7}$ & - & + & + & - \\
SNC & - & - & - & - \\
NO & - & - & - & - \\
\hline
\end{tabular}

$\overline{\mathrm{CPC}}=$ Controle positivo de Campylobacter fetus, $\mathrm{CPH}=$ Controle positivo de Haemophilus somnu, CPL = Conrole positivo de Leptospir ainterrogans sorovar Pomona, $\mathrm{CPB}=$ Controle positivo de Brucella abortus, SNC = Sêmen não contaminado, NO = Controle negativo (sem DNA), + Resultado positivo, - Resultado negativo.

sêmen quanto à presença de bactérias no sêmen (Santurde et al. 1996, Rocha et al. 1998, Travassos et al. 1999, Smits et al. 2000, Ortega-Mora et al. 2003, Mukhufhi et al. 2003).

Além dos testes clássicos oficialmente reconhecidos pelo Ministério da Agricultura, Pecuária e Abastecimento (MAPA) e organismos internacionais competentes para detecção de patógenos World Organization For Animal Health (OIE), na grande maioria baseados em ensaios imunológicos, o desenvolvimento de metodologias que identifiquem diretamente a presença das bactérias em questão devem ser implantadas futuramente para o controle sanitário de centrais de inseminação artificial (OIE 2008).

Dentre as diversas bactérias listadas pela OIE que afetam a bovinocultura (Thibier \& Guerin 2000), algumas têm papel de relevante importância na situação brasileira como, por exemplo, a Brucella abortus (Poster et al. 2002) a Leptospira sp (Heinemann et al. 2000) e o Campylobacter fetus (Vargas et al. 2003). Outra bactéria que apresenta significância econômica em outros países, mas que não foi ainda devidamente estudada no Brasil é Haemophilus somnus (Tegtmeier et al. 2000).

Os resultados da amplificação de DNA de amostras de sêmen contaminado experimentalmente com Brucella abortus, Leptospira interrogans sorovar pomona, Haemophilus somnus e Campylobacter fetus pela técnica de PCR (Fig.1), mostraram que os oligonucleotídeos iniciadores empregados em estudos anteriores (Leal-Klevezas et al. 1995, Mérien et al. 1992, Angen et al. 1998), bem como aqueles gerados neste trabalho para Campylobacter resultaram em amplificações específicas para o DNA destes agentes infecciosos não ocorrendo interferência do DNA não bacteriano ou das outras bactérias analisadas neste tipo de material biológico.

Vários autores relataram previamente o emprego da técnica de PCR para detecção destes patógenos em amos- 
tras biológicas de diversas origens: sangue e leite de animais infectados (Leal-Klevezas et al. 1995) amostras de tecidos do pulmão (Tegtmeier et al. 2000), fetos abortados (Leyla et al. 2003).

Analisando especificamente amostras de sêmen, Amin et al. (2001) relataram a utilidade da técnica de PCR para a detecção de Brucella militensis em sêmen caprino e Manterola et al. (2003) avaliaram a PCR na detecção de Brucella ovis em sêmen ovino com sucesso.

Os dados do presente estudo confirmam as informações de trabalhos anteriores envolvendo a detecção de Leptospira em sêmen bovino (Masri et al. 1997, Heinemann et al. 1999, 2000, Dias et al. 2006). Entretanto, com relação às bactérias Brucella, Haemophilus e Campylobacter, não foi possível estabelecer essa correlação, pois não foi encontrado nenhum relato no qual se utilizou o sêmen como amostra experimental para a detecção simultânea destas bactérias.

O uso de marcação fluorescente acoplada ao PCR multiplex, com posterior detecção em sistema automático de análise de fragmentos pode ser uma alternativa para o incremento desta aplicação (Englund et al. 2001, Checa et al. 2002, Myong Song et al. 2003).

Poucos são os artigos que reúnem a amplificação de batérias por PCR com sua detecção em sistema automático para análise de fragmentos de DNA marcados com fluorocromos em um mesmo ensaio. Englund et al. (2001) compararam a detecção de Mycobacterirum avium subespécie paratuberculosis em amostras biológicas de aves utilizando PCR simples, PCR fluorescente e nested-PCR. Este foi o primeiro e único artigo descrevendo essa aplicação até o momento. Neste estudo os autores afirmaram que o PCR fluorescente constitui-se em alternativa útil ao PCR simples e nested PCR para a detecção destas bactérias devido à maior sensibilidade e capacidade conferida pela automação.

Para avaliar a eficiência do sistema de eletroforese capilar acoplado à detecção da marcação fluorescente em PCR multiplex na detecção simultânea das quatro bactérias em questão no sêmen bovino, foram desenhados experimentos que visaram a união primeiramente de Brucella e Leptospira, seguida de Brucella, Leptospira e Haemophilus, e finalmente Brucella, Leptospira, Haemophilus e Campylobacter. A análise por eletroforese capilar revelou positividade até a diluição de $10^{-3}$ bactérias $/ \mathrm{mL}$ das concentrações iniciais das soluções estoque de Brucella, Leptospira, Haemophilus e Campylobacter, revelando maior sensibilidade quando comparada à análise tradicional pela eletroforese em gel de poliacrilamida na qual se observou sinal positivo até $10^{-2}$ bactérias/mL como estão demonstrados no Quadro 3 e na Figura 1, respectivamente, sugerindo a consistência da técnica e a melhor capacidade de detecção dos fragmentos de DNA pela eletroforese capilar.

Richtzenhain et al. (2002) descreveram a aplicação com sucesso da técnica de PCR multiplex para detecção de Leptospira spp. e Brucella spp. em amostras de fetos bovinos abortados, e sugeriu o uso do teste multiplex para esses dois agentes na rotina de diagnóstico de enfermidades causadoras de abortos em bovinos. Os dados do presente trabalho mostram que a introdução de mais bactérias ao sistema PCR multiplex utilizado por Richtzenhain et al. (2002) pode ser de grande valia para o diagnóstico diferencial das doenças da reprodução. Tramuta et al. (2011) descreveram cinco PCR mutiplex para detecção simultânea dos principais agentes infecciosos responsáveis pelo aborto bovino dentre eles Brucella spp., Leptospira spp. e Campylobacter fetus demonstrando o quanto os ensaios de PCR multiplex podem ser mais rápidos para detecção destes agentes simultaneamente que a detecção individual de cada agente na PCR simples.

A análise de fragmentos de PCR fluorescente por eletroforese capilar no diagnóstico de doenças infecciosas pode ser considerada ainda pouco estudada, entretanto a melhor capacidade de detecção por esse método observada ao longo dos experimentos desenvolvidos no presente trabalho revelou ser ampliada pelo menos 10 vezes em comparação a eletroforese tradicional em gel de poliacrilamida.

\section{CONCLUSÕES}

Aliada à eletroforese capilar, a técnica de PCR multiplex permitiu a detecção dos quatro patógenos no sêmen bovino com maior rapidez e sensibilidade quando comparado ao método tradicional de eletroforese em gel de poliacrilamida; vantagens estas que poderão ser adicionadas aos métodos convencionais de diagnóstico.

A técnica de PCR multiplex aliada à eletroforese capilar foi usada pela primeira vez para o diagnóstico direto de quatro bactérias patogênicas no sêmen, demonstrando ser um método rápido na detecção de bactérias causadoras de doenças reprodutivas.

\section{REFERÊNCIAS}

Amin A.S. 2003. Comparison of polymerase chain reaction and cell culture for the detection of Chlamydophila species in the semen of bulls, buffalo-bulls and rams. Vet. J. 166:86-92.

Amin A.S., Hamdy M.E.R. \& Ibrahim A.K. 2001. Detection of Brucella melitensis in semen using the polymerase chain reaction assay. Vet. Microbiol. 83:37-44.

Angen, O. Ahrens P. \& Tegtmeier C. 1998. Development of a PCR test for identification of Haemophilus somnus in pure and mixed cultures. Vet. Microbiol. 63:39-48.

Bor P., Hindkjar J., Kolvraa S. \& Ingerslev H.J. 2003. A new approach for screening for Y microdeletions: capillary electrophoresis combined with fluorescent multiplex PCR. J. Assisted Reprod. Genet. 20:46-51.

Bricker B.J. 2002. PCR as a diagnostic tool for brucellosis. Vet. Microbiol. 90:435-446.

Checa M. L., Dunner S. \& Canón J. 2002. Prediction of X and Y chromosome content in bovine sperm by using DNA pools through capillary electrophoresis. Theriog. 58:1579-1586.

Ciceroni L., Ciarrocchi S., Ciervo A., Petrucca A., Pinto A., Calderaro A., Viani I., Galati L., Dettori G. \& Chezzi C. 2002. Differentiation of leptospires of the serogroup pomona by monoclonal antibodies, pulsed-field gel electrophoresis and arbitrarily primed polymerase chain reaction. Res. Microbiol. 153:37-44.

Dias F.E.F., Aoki S.M., Mesquita L.G., Nunes C.M. \& Garcia J.F. 2006. Dectecção de Leptospira pomona em sêmen bovino por eletroforese capilar. Braz. J. Vet. Res. Anim. Sci. 43:394-399.

Englund S., Bolske G., Ballagi-Pordány A. \& Johansson K.E. 2001. Detection of Mycobacterium avian subsp. paratuberculosis in tissue samples by single, fluorescent and nested PCR based on the IS900 gene. Vet. Microbiol. 81:257-271. 
Heinemann M.B., Garcia J.F., Nunes C.M., Gregori F., Higa Z.M.M., Vasconcellos S.A. \& Richtzenhain L.J. 2000. Detection and differentiation of Leptospira spp serovars in bovine semen by polymerase chain reaction and restriction fragment length polymorphism. Vet. Microbiol. 73:261-267.

Heinemann M.B., Garcia J.F., Nunes C.M., Morais Z.M., Gregori F. Cortez A., Vasconcellos S.A., Visintin J.A. \& Richtzenhain L.J. 1999. Detection of Leptospires in bovine semen by polymerase chain reaction. Aust. Vet. J. 77:32-34.

Kim J., Um Han D., Choi C. \& Chae C. 2003. Simultaneous detection and differentiation between porcine Circovirus and Porcine Parvovirus in boar semen by multiplex seminested polymerase chain reaction. J. Vet. Med. Sci. 65:741-744.

Kim J., Um Han D., Choi C. \& Chae C. 2001. Differentiation of porcine circovirus (PCV) -1 and PCV-2 in boar semen using a multiplex nested polymerase chain reaction. J. Virol. Meth. 98:25-31.

Leal-Klevezas D.S., Martínez-Vázquez I.O., López-Merino A. \& Martínez-Soriano J.P. 1995. Single-step PCR for detection of Brucella spp. from blood and milk of infected animals. J. Clin. Microbiol. 33:3087-3090.

Leyla G., Kadri G. \& Umran O. 2003. Comparison of polymerase chain reaction and bacteriological culture for the diagnosis if sheep brucellosis using aborted fetus samples. Vet. Microbiol. 93:53-61.

Lunge V.R., Simon D. \& Ikuta N. 2003. Métodos de diagnóstico genético-molecular, p.27-45. In: Marques E.K. (Ed.), Diagnóstico Genético-Molecular. ULBRA, Canoas. 372 p.

Manterola L., Tajero-garces A., Ficapal A., Shopayeva G., Blasco J.M., Marin C.M. \& Lopez-Goni I. 2003. Evaluation of a PCR test for the diagnosis of Brucella ovis infection in semen samples from rams. Vet. Microbiol. 92:65-72.

Markoulatos P., Siafakas N. \& Moncany M. 2002. Multiplex polymerase chain reaction: a practical approach. J. Clin. Lab. Anal. 16:47-51.

Masri S.A., Nguyen P.T., Gale S.P., Howard C.J. \& Jung S. 1997. A polymerase chain reaction assay for the detection of Leptospira spp in bovine semen. Can. J. Vet. Res. 6:15-20.

Mérien F., Amouriax P., Perolat P., Baranton G. \& Saint Girons I. 1992. Polymerase chain reaction for detection of Leptospira spp in clinical samples. J. Clin. Microbiol. 30:2219-2224.

Mukhufhi N., Irons P.C., Michel A. \& Peta F. 2003. Evaluation of a PCR test for the diagnosis of Tritrichomonas foetus infection in bulls: effects of sample collection methods, storage and transport medium on the test. Theriog. 60:1269-1278.

Myong Song M., Mobely J. \& Vo-Dinh T. 2003. Detection of bacterial pathogen DNA using am integrated complementary metal oxide semiconductor microchip system with capillary electrophoresis. J. Chrom. B, Analyt. Technol. Biomed. Life Sci. 783:501-508.

Ortega-Mora L.M., Ferre I., Del-Pozo I., Caetano-da-Silva A., Collantes-Fernandez E., Regidor-Cerrillo J., Ugarte-Garagalza C. \& Aduriz G. 2003. De- tection of Neospora caninum in semen of bulls. Vet. Parasitol. 117:301308.

Poester F.P., Gonçalves V.S.P. \& Lage A.P. 2002. Brucellosis in Brazil. Vet. Microbiol. 90:55-62.

Richtzenhain L.J., Cortez A, Heinemann M.B., Soares,R.M., Sakamoto S.M., Vasconcellos S.A., Higa Z.M.M., Scarelli E. \& Genovez M.E.A 2002. multiplex PCR for detection of Brucella spp.and Leptospira spp. DNA from aborted bovine fetuses. Vet. Microbiol. 87:139-147.

Rocha M.A., Barbosa E.F., Guimaraes S. E.F., Dias Neto E. \& Gouveia A.M.G. 1998. A high sensitivity-nested PCR assay for BHV-1 detection in semen of naturally infected bulls. Vet. Microbiol. 63:1-11.

Rodrigues A.L.B., Girio R.J.S., Esper C.R., Rodrigues L.H., Magajevski F.S. \& Oliveira M.A. 2003. Sobrevivência da Leptospira interrogans sorovariedade pomona em sêmen bovino experimentalmente contaminado. Revta Bras. Reprod. Anim. 27:636-643.

Santurde G., Silva N., Villares R., Tabarés E., Solana A., Bautista J M. \& Castro J.M. 1996. Rapid and high sensitivity test for direct detection of bovine herpes virus-1 genome in clinical samples. Vet. Microbiol. 49:81-92.

Smits C.B., Van Maanen C., Glas R.D., De Gee A.L.W., Dijkstrab T., Van Oirschot J.T. \& Rijsewijk F.A.M. 2000. Comparison of three polymerase chain reaction methods for routine detection of bovine herpes virus 1 DNA in fresh bull semen. J. Virol. Meth. 85:65-73.

Stephen F.A., Thomas L.M., Alejandro A.S., Jinghui Z., Zheng Z., Webb M. \& David J.L. 1997. Gapped BLAST and PSI-BLAST: a new generation of protein database search programs, Nucleic Acids Res. 25:3389-3402.

Tegtmeier C., Angen O. \& Ahrens P. 2000. Comparison of bacterial cultivation, PCR, hybridization and immunohistochemisty as tool for diagnosis of Haemophilus somnus in peneumoniain cattle. Vet. Microbiol. 76:385394.

Thibier M. \& Guerin B. 2000. Hygienic aspects of storage and use of semen for artificial insemination. Anim. Reprod. Sci. 62:233-251.

Tramuta C., Lacerenza D., Zoppi S., Goria M., Dondo A., Ferroglio E., Nebbia P. \& Rosati S. 2011. Development of a set of multiplex standard polymerase chain reaction assays for the identification of infectious agents from aborted bovine clinical samples. J. Vet. Diagn. Invest. 23:657-664

Travassos C.E., Benoit C., Valas S., Silva A.G. \& Perrin G. 1999. Caprine arthritis-encephalitis virus in semen of naturally infected bucks. Small Rum. Res. 32:101-106.

Vargas A.C., Costa M.M., Vainstein M.H., Kreutz L.C. \& Neves J.P. 2003. Phenotypic and molecular characterization of bovine Campylobacter fetus strains isolated in Brazil. Vet. Microbiol. 93:121-132.

Wang G., Clark C.G., Taylor T.M., Puncknell C., Barton C., Price L., Woodward D.L. \& Rodgers F.G. 2002. Colony multiplex PCR assay for identification and differentiation of Campylobacter jejuni, C. coli, C. lari, C. upsaliensis, and $C$. fetus subsp. fetus. J. Clin. Microbiol. 40:4744-4747. 